\title{
Once in a Blue Moon, Congenital Anterior Urethral Diverticulum
}

\author{
${ }^{1}$ Rohit Juneja, ${ }^{2}$ L Manjunath, ${ }^{3} \mathrm{HS}$ Veerendra, ${ }^{4}$ Ananth S Mathad
}

\begin{abstract}
Anterior urethral valves (AUVs) are rare congenital anomalies causing lower urinary tract obstruction in children. Although they are referred to as valves, these obstructive structures often occur in the form of a diverticulum. Congenital anterior urethral diverticulum (CAUD) is an uncommon/rare entity in children which can lead to obstructive lower urinary tract symptoms and urosepsis. Over the past 20 years, more than 260 cases have been reported. However, most cases are diagnosed on prenatal ultrasonography (USG) in early life if patients present with bilateral hydronephrosis and/or azotemia. Diagnosis is by ureteroscopy and radiological imaging. Surgical treatment can be open or endoscopic. Here, we report a new case of CAUD and discuss its clinical presentation, diagnosis, and management. A brief review of the literature is also presented.
\end{abstract}

Keywords: Anterior urethral diverticulum, Anterior urethral valves, Congenital anterior urethral diverticulum, Micturating cystourethrogram, Transurethral resection, Ultrasonography.

How to cite this article: Juneja R, Manjunath L, Veerendra HS, Mathad AS. Once in a Blue Moon, Congenital Anterior Urethral Diverticulum. Int J Recent Surg Med Sci 2018;4(1):32-36.

\section{Source of support: Nil \\ Conflict of interest: None}

\section{INTRODUCTION}

Anterior urethral valves (Fig. 1) are rare congenital anomalies causing lower urinary tract obstruction in children. Although they are referred to as valves, these obstructive structures often occur in the form of a diverticulum. Anterior urethral diverticulum (AUD) may be classified as congenital or acquired. Acquired diverticulum is more common than the congenital variety and urethral trauma, catheterization or instrumentation, infection, and obstruction can play a role in its pathophysiology. ${ }^{1}$

\footnotetext{
${ }^{1,4}$ Resident, ${ }^{2,3}$ Associate Professor

${ }^{1,3}$ Department of Urology, SS Institute of Medical Sciences and Research Centre, Davangere, Karnataka, India

${ }^{2}$ Department of Paediatric Urology, SS Institute of Medical Sciences and Research Centre, Davangere, Karnataka, India

${ }^{4}$ Department of General Surgery, SS Institute of Medical Sciences and Research Centre, Davangere, Karnataka, India

Corresponding Author: Rohit Juneja, Resident, Department of Urology, SS Institute of Medical Sciences and Research Centre, Davangere, Karnataka, India, Phone: +919108927347 e-mail: rj.juneja@gmail.com
}

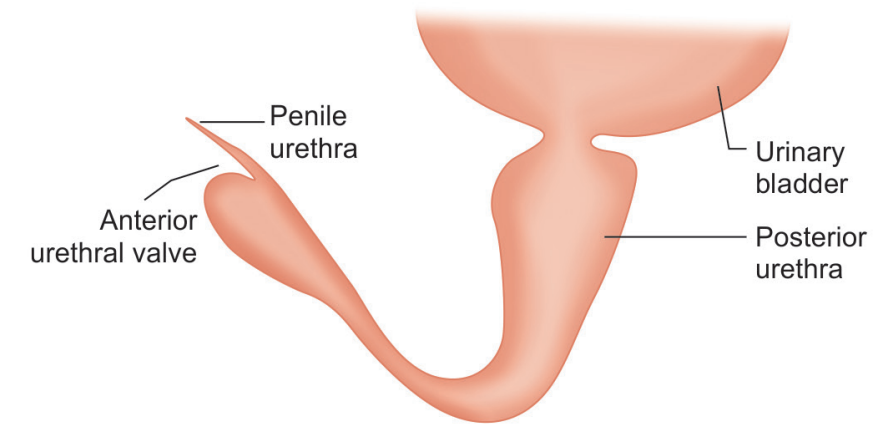

Fig. 1: Anterior urethral valve

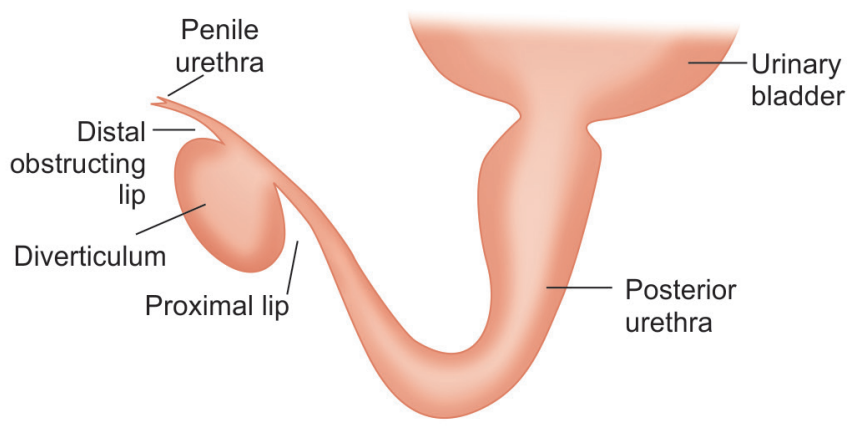

Fig. 2: Anterior urethral diverticulum

The CAUD (Fig. 2) is classified into saccular variety and globular variety, the former being more common than the latter. ${ }^{2}$ Several possible causes of the congenital diverticulum have been suggested, including a developmental defect of the corpus spongiosum, cystic dilatation of the urethral glands, and sequestration of an epithelial nest after closure of the urethral folds. ${ }^{3}$ The cause and effect relationship between AUD and AUV has been extensively debated. Some authors do not distinguish between AUD and AUV, while others believe that these are different entity. The diverticulum that is associated with AUV is not a true diverticulum because in AUD, an acute angle is formed between the proximal part of dilated portion and the ventral floor, whereas this acute angle is not present in AUV. ${ }^{4}$ Over the past 20 years, more than 260 cases have been reported. ${ }^{5}$

The clinical presentation of CAUD is highly variable, depending on the child's age and the degree of obstruction. ${ }^{6-9}$ It causes obstruction of male urethra and complaints of dysuria, dribbling of urine, recurrent urinary tract infection (UTI), or a fluctuant ventral penile 
swelling. ${ }^{10}$ However, most cases are diagnosed on prenatal USG in early life if patients present with bilateral hydronephrosis and/or azotemia. ${ }^{6-9}$

The treatment options in AUD include endoscopic division of distal lip of diverticulum, ${ }^{11}$ excision of diverticulum with primary repair, ${ }^{12}$ marsupialization with staged urethroplasty, or even suprapubic diversion followed by definitive repair. ${ }^{13}$

Here, we report a new case of CAUD and discuss its clinical presentation, diagnosis, and management. A brief review of the literature is also presented.

\section{CASE REPORT}

We report the case of a 1-year-old child presented to pediatric urology outpatient department with complaints of dribbling urine and swelling on the surface of penis since birth. His parents gave history that he never had a good urinary stream, with dribbling and used to have intermittent spikes of fever with recurrent UTIs. They denied any history of trauma, burning micturition, or urethral instrumentation. There was no unusual antenatal history. On examination (Fig. 3), swelling on the ventral aspect of the penile urethra was present. Swelling was soft, cystic, fluctuant, and compressible, collapsed completely on manual compression with urine coming per urethral. Lab studies showed normal urine analysis, routine blood counts, blood urea, and creatinine. Ultrasound kidney, ureter, and bladder was normal with no hydronephrosis or hydroureter; kidneys and bladder were normal. Retrograde urethrography was done, suggestive of the presence of diverticulum at the level of penile urethral (Fig. 4). Findings were again confirmed on cystopanendoscopy. Patient underwent open diverticulectomy and urethroplasty for the same (Fig. 5). Foley removal was done at 10 th postoperative day. Postoperative period was uneventful (Fig. 6). Follow-up of patient was normal after 3 months with good urinary stream and no urinary complaints.

\section{DISCUSSION}

Congenital anterior urethral diverticulum may be found all along the anterior urethra, but is usually located
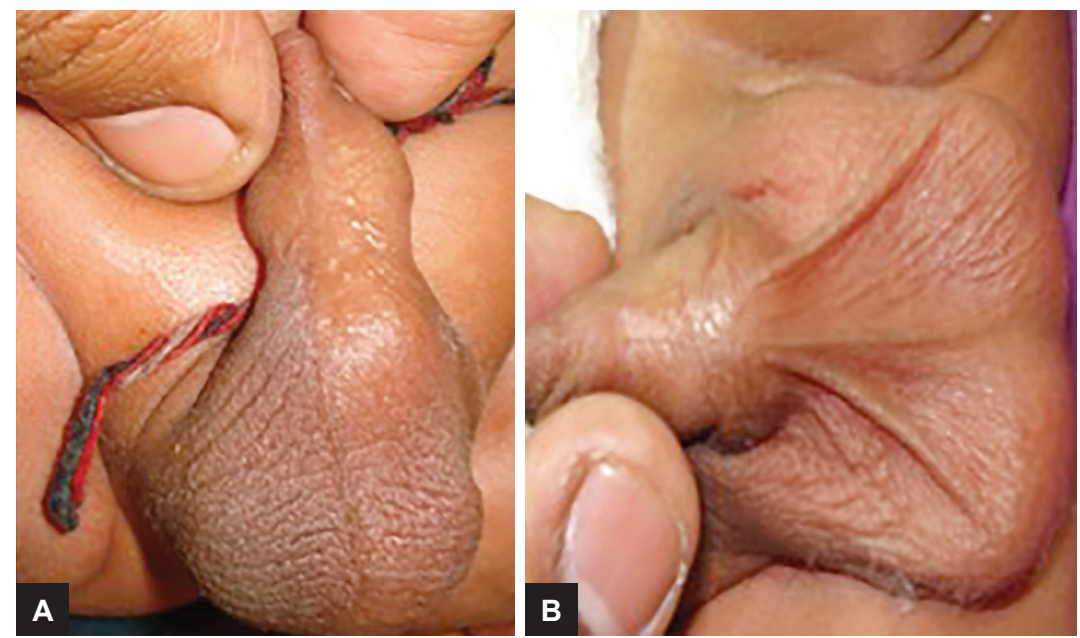

Figs $3 \mathrm{~A}$ and $\mathrm{B}$ : Cystic swelling at the penoscrotal junction
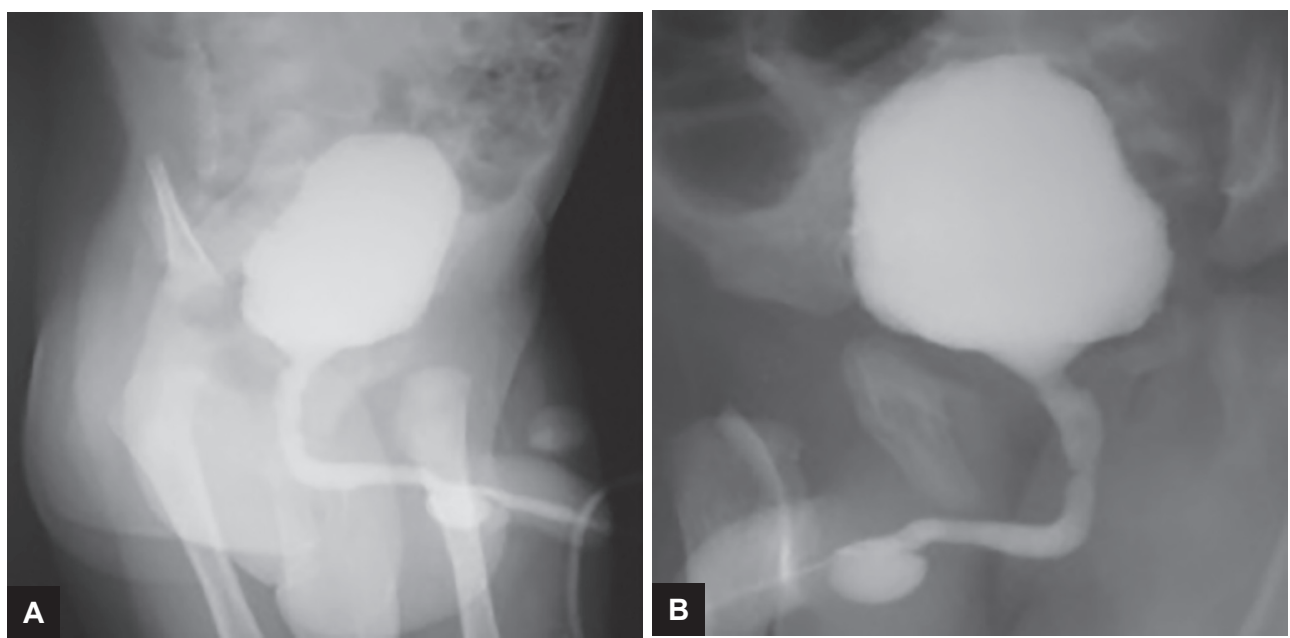

Figs 4A and B: Retrograde urethrography s/o diverticulum at penile urethral 


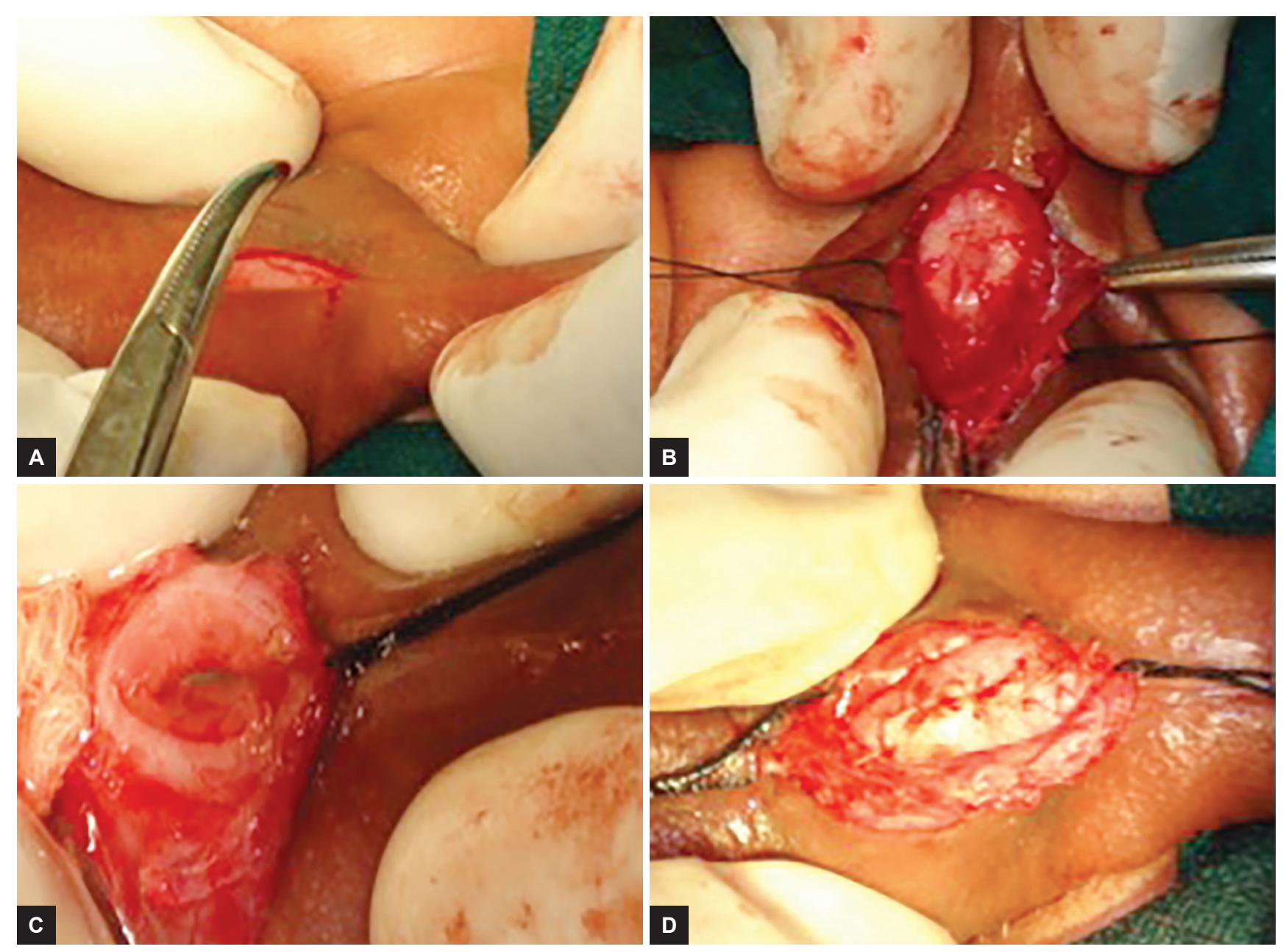

Figs 5A to D: Intraoperative findings and procedure

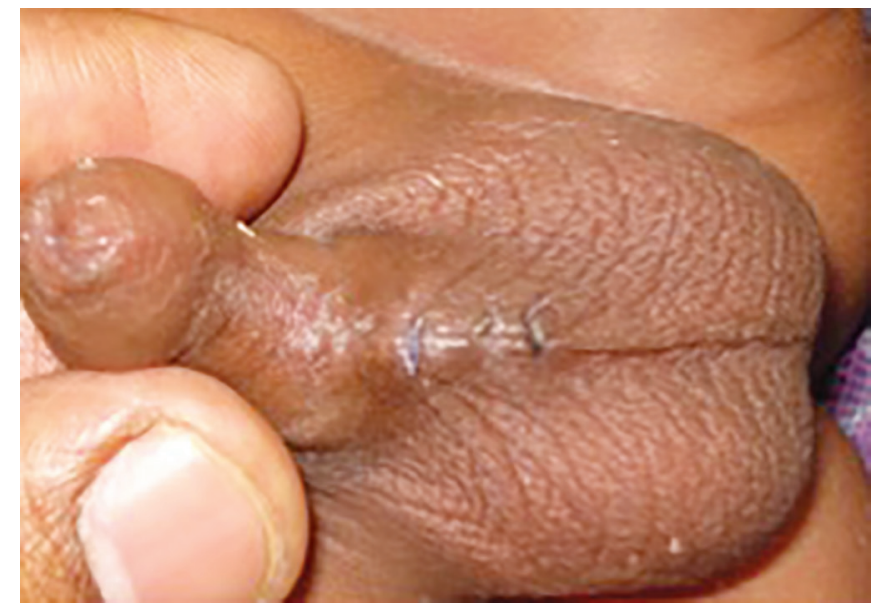

Fig. 6: Postoperative view

between the bulbous and the mid-penile urethra, mostly on the ventral surface and in the anterior urethra with diameter typically between 3 and $5 \mathrm{~cm} \cdot{ }^{14-17}$

The embryology remains unclear. No family pattern of inheritance has been detected yet. ${ }^{5}$ The etiology of this rare condition has provoked controversy for years. Various hypotheses include a developmental defect of the corpus spongiosum, cystic dilatation of the peri-urethral glands, ruptured syringocele, incomplete hypospadias, incomplete fusion of a segment of the urethral plate, and sequestration of an epithelial nest after closure of the urethral folds. ${ }^{5,-9,18-20}$ Suter ${ }^{21}$ proposed a theory that a diverticulum of the urethra develops because of epidermal pockets communicating with the ventral urethral wall.

A urethral dilatation in this region, in the absence of a corpus spongiosum, may develop into a diverticulum. ${ }^{3}$

Diverticula can be described as saccular or diffuse. The saccular type is a localized protrusion from the urethral lumen into the ventral wall of the anterior urethra, and the diffuse type is a generalized dilatation of the entire anterior urethra. A congenital saccular diverticulum may produce anterior urethral obstruction by a valve-like mechanism of its distal lip, which obscures the urethral lumen during filling. ${ }^{22,23}$ In this case, they would not be true diverticula. In a true CAUD, an acute angle is formed between the proximal part of the dilated portion and the ventral floor. ${ }^{4}$

The primary differential diagnostic considerations include AUV, dilated Cowper's gland ducts, and posttraumatic diverticulum. ${ }^{24}$ 
The presence of a penile or penoscrotal mass clinically and radiologically, which is seen as an accurate filling defect, distinguishes the diverticulum from the valve. Also, the proximal lip of the diverticulum forms an acute angle with the rest of the urethra, while the anterior valve forms the obtuse angle. ${ }^{24,25}$ In dilated Cowper's gland ducts, a tubular channel is seen in the ventral surface of the bulbous urethra which it parallels. Its termination is in the urogenital diaphragm. ${ }^{24,25}$

Congenital anterior urethral diverticulum may present itself at any age, from infant to adult. Generally, one-third of cases are diagnosed in the neonatal period and onehalf by 2 years of age in patients who have never been catheterized urethrally. ${ }^{5}$

Newborns and infants present with symptoms, such as fever, diarrhea, and vomiting. ${ }^{10,14,26}$ Most children with this condition present with difficulty in initiating micturition, dribbling of urine, poor urinary stream, or UTI. A careful history will reveal that these children never had a good urinary stream since birth, and the telltale sign is a cystic swelling at the penile urethra. ${ }^{27}$ If it is uninfected and without complication, the mass is unattached to the overlying skin, nontender, and mobile laterally. ${ }^{27}$ On compression, urine is seen dribbling out of the external meatus, and the swelling is seen to deflate. ${ }^{27}$

Diagnosis is usually made by micturating cystourethrogram (MCUG) or retrograde urethrogram. The MCUG has the additional advantage of demonstrating proximal changes, such as megacystis, vesicoureteral reflux, or other associated anomalies. The USG complements the contrast studies to diagnose the condition and offers the additional advantage of evaluating the upper tracts as well. Moreover, voiding USG has been found to be an alternative to the contrast studies in making a diagnosis of AUD. ${ }^{28}$ Cystourethroscopy is diagnostic as well as therapeutic. A diverticulum typically appears as an outpouching from the ventral wall of the urethra and has a proximal and distal rim. ${ }^{29}$

Treatment of AUD depends on the type with size of the diverticulum and the degree of obstruction. They can be managed by endoscopic or open surgical excision. For small anterior diverticula, transurethral resection with a pediatric resectoscope is the treatment of choice in well-supported diverticula wherein the distal obstructing lip is resected. ${ }^{14-16,18,22,29}$ However, this does not always eliminate urinary stasis or the bulging of the diverticulum..$^{5,30}$ Moreover, successful treatment of AUD has also been reported by using a Sachse knife. ${ }^{31}$ For large diverticula, as in our cases, open diverticulectomy and primary repair are recommended. This approach may provide a more uniform caliber of urethra, but there is a risk of urethrocutaneous fistula formation. ${ }^{5,17,18}$
Quoraishi et al ${ }^{32}$ adopted an endoscopic approach with incision of the lip of the diverticulum. However, these patients can again develop a flap, requiring repeat procedures.

In our case, we used the technique of plication of the redundant diverticular wall with good result. ${ }^{33}$ Some authors have also advocated making a triangular flap which is fitted into the distal lip and double breasting of the urethral suture line, as described in literature. ${ }^{12}$

In situations where there are back pressure changes of upper tracts with deranged renal function, urinary diversion, either by marsupialization of the diverticulum or even suprapubic cystostomy/vesicostomy is a safer option. ${ }^{11,13}$

In summary, a history of poor urinary stream and dribbling, recurrent UTI, and a palpable penile or penoscrotal mass on physical examination strongly suggest the diagnosis of CAUD. A MCUG will confirm the diagnosis. Early surgical intervention prevents the onset of uremia.

\section{REFERENCES}

1. Allen D, Mishra V, Pepper W, Shah S, Motiwala H. A singlecentre experience of symptomatic male urethral diverticula. Urology 2007 Oct;70(4):650-653.

2. Johnson FB. Diverticula and cysts of the urethra. J Urol 1923 Oct;10(4):295-310.

3. Rawat J, Khan TR, Singh S, Maletha M, Kureel S. Congenital anterior urethral valves and diverticula: diagnosis and management in six cases. Afr J Paediatr Surg 2009 Jul-Dec;6(2): 102-105.

4. Huang CJ, Bai JW, Liang RX, Sun N. Congenital anterior urethral valves and diverticula-analysis of 50 cases. Ann Acad Med Singapore 1989 Dec;18(6):665-668.

5. Paulhac P, Fourcade L, Lesaux N, Alain JL, Colombeau P. Anterior urethral valves and diverticula. BJU Int 2003Sep;92(5): 506-509.

6. McLellan DL, Goston MV, Diamond DA, Lebowitz RL, Mandell J, Atala A, Bauer SB. Anterior urethral valves and diverticula in children: a result of ruptured Cowper's duct cyst? BJU Int 2004 Aug;94(3):375-378.

7. Kadian YS, Rattan KN, Singh M, Kajal P. Congenital anterior urethral diverticulum in children: a case report and review. ISRN Surg 2011 Jun;2011:120307.

8. Kajbafzadeh AM, Payabvash S, Karimian G. Urodynamic changes in patients with anterior urethral valves: before and after endoscopic valve ablation. J Pediatr Urol 2007 Aug;3(4): 295-300.

9. Aygün C, Güven O, Tekin MI, Peşkircioğlu L, Ozkardeş H. Anterior urethral valve as a cause of end-stage renal disease. Int J Urol 2001 Mar;8(3):141-143.

10. Ortlip SA, Gonzalez R, Williams RD. Diverticula of the male urethra. J Urol1980 Sep;124(3):350-355.

11. Zia-ul-Miraj M. Congenital anterior urethral diverticula in children. Pediatr Surg Int 1999;15(8):567-569.

12. Bhatnagar V, Lal R, Mitra DK. Primary reconstruction of a congenital anterior urethral diverticulum. Pediatr Surg Int 1999;15(3-4):294-295.

13. Gupta DK, Srinivas M. Congenital anterior urethral diverticulum in children. Pediatr Surg Int 2000 Nov;16(8):565-568. 
14. Rafique M. Congenital anterior urethral diverticulum in an adolescent boy with obstructive urinary symptoms. Int Urol Nephrol 2007 Feb;39(2):437-440.

15. Singh SK, Ansari Ms. Congenital anterior urethral diverticulum. Turk J Urol 2014 Sep;40(3):182-184.

16. Gopalkrishna A, Sharma SM, Ananda B. Anterior urethral diverticulum: a rare presentation. Indian J Plast Surg 2016 May-Aug;49(2):265-267.

17. Smith GH, Deshpande AV, Tang RW. Uncommon causes of anterior urethral diverticula in children: two cases and review of literature. Urol Ann 2014 Jan;6(1):75-79.

18. Tank ES. Anterior urethral valves resulting from congenital urethral diverticula. Urology 1987 Nov;30(5):467-469.

19. Howieson AJ, MacKinlay GA. Giant anterior urethral diverticulum in a neonate. J Pediatr Surg 2007 Apr;42(4):735-736.

20. Song JH, Lee MH, Lee JH, Lee CH, Jeon YS, Lee NK, Kim DS. Anterior urethral valve and diverticulum in a neonate with febrile urinary tract infection. Korean J Urol 2012 Jul;53(7): 505-507.

21. Suter F. Ein Beitrag zur histologic and genese der congenitalen divertikel der mannlichen hornrorhe. Archiv Fur Klinische Chair 1908;87:225-242.

22. Walsh, P.; Retik, A.; Vaughan, E Jr.; Wein, A.; editors. Campbell's urology. 8th ed. Philadelphia (PA): WB Saunders Elsevier; 2002. pp. 2225-2226.

23. Barnewolt, CE.; Paltiel, HJ.; Lebowitz, RL.; Kirks, DR. Genitourinary tract. In: Kirks DR, Thorne Griscom N, editors.
Practical pediatric imaging: diagnostic radiology of infants and children. 3rd ed. Philadelphia (PA): Lippincott-Raven; 1998. pp. 1009-1170.

24. Kirks DR, Grossman H. Congenital saccular anterior urethral diverticulum. Radiology 1981 Aug;140(2):367-372.

25. Kretschmer HL. Diverticula in the anterior urethra in male children. Surg Gynecol Obstet 1936;62:634-640.

26. Smith SE. Unexpected anterior urethral diverticula. Clin Radiol 1986 Jan-Nov;37(1):55-58.

27. Cheong WY, Cheng HK, Tan KP. Congenital anterior urethral diverticulum. Singapore Med J 1988 Apr;29(2):171-175.

28. Goyal M, Sharma R, Gupta DK, Sharma A, Berry M. Congenital anterior urethral diverticulum: sonographic diagnosis. J Clin Ultrasound 1996 Nov-Dec;24(9):543-544.

29. Heaton BW, Snow BW, Cartwright PC. Repair of urethral diverticulum by plication. Urology 1994 Nov;44(5):749-752.

30. Kajbafzadeh A. Congenital urethral anomalies in boys. Part II. Urol J 2005 Summer;2(3):125-131.

31. Netto Junior NR, Lemos GC, Claro JF, Hering FL. Congenital diverticulum of male urethra. Urology 1984 Sep;24(3): 239-242.

32. QuoraishiSH, Khan F, Besarani D, Patil K. Congenital anterior urethral diverticulum in a male teenager: a case report and review of the literature. Case Rep Urol 2011 Sep;2011:738638.

33. Rushton HG, Parrott TS, Woodard JR, Walther M. The role of vesi-costomy in the management of anterior urethral valves in neonates and infants. J Urol 1987 Jul;138(1):107-109. 